\title{
Is iron deficiency in children a risk factor in chronic otitis media with effusion?
}

\begin{abstract}
Objective: Otitis media with effusion (OME) is a childhood disorder that can cause hearing loss. Chronic long-term hearing loss can affect children's ability to learn and may result in decreased intellectual ability during adulthood. Iron deficiency anemia is a common nutritional insufficiency in childhood. These two pathologies, which both appear frequently and often manifest during childhood, are evaluated.
\end{abstract}

Methods: Clinically pre-diagnosed patients with chronic otitis media with effusion (COME) were verified by tympanogram. Participants included 81 patients with COME and 81 healthy individuals. Hemoglobin, MCV, serum iron, and ferritin values were compared between these two groups.

Results: No statistically significant differences were observed in all parameters in terms of hemoglobin, MCV, serum iron, and ferritin between the COME group and the control group. However, all parameters were low in the COME group.

Conclusion: These results suggest that iron deficiency cannot be added to the risk factors of OME.

Keywords: iron deficiency, children, risk factor, effusion, otitis media
Volume 10 Issue 4 - 2018

\author{
Muhammet Recai Mazlumoglu \\ Hinis Sehit Yavuz Yurekseven State Hospital, \\ Otorhinolaryngology Clinic, Turkey
}

Correspondence: Muhammet Recai Mazlumoglu, Hinis Sehit Yavuz Yurekseven State Hospital, Otorhinolaryngology Clinic, Erzurum, Turkey, Tel +905424355835,

Email dr.mazlumoglu@gmail.com

Received: January 08, 2018| Published: July 18, 2018
Abbreviations: OME, otitis media with effusion; COME, chronic otitis media with effusion; TIBC, total iron binding capacity; $\mathrm{Hgb}$, hemoglobin; CRP, C-reactive protein; AOM, acute otitis media

\section{Introduction}

Otitis media with effusion (OME) is characterized by an accumulation of adhesive fluid behind the tympanic membrane, and generally occurs in children. When this condition continues for three months, it is classified as chronic otitis media with effusion (COME). ${ }^{1,2}$ OME is the most common cause of hearing loss in childhood worldwide and affects about $80 \%$ of children. ${ }^{3}$ Risk factors for COME can be summarized as age, ethnicity, and family history, inadequate intake of breast milk, upper respiratory tract infections, and congenital malformations of the upper respiratory tract..$^{2-4}$

Iron deficiency is the most common type of malnutrition worldwide and is a major health problem, especially in developing countries. According to the World Health Organization, 30\% of children aged $0-4$ and $48 \%$ of children aged $5-14$ in developing countries are anemic. $^{5}$ The laboratory tests frequently used in determining iron deficiency include hemoglobin ( $\mathrm{Hgb}), \mathrm{MCV}$, serum iron, ferritin, and total iron binding capacity (TIBC). Among these parameters, TIBC increases in iron deficiency while the others decrease. ${ }^{6}$

\section{Methods}

The study was conducted between June 2015 and June 2016. Ethics committee approval was obtained from Regional Education and Research Hospital (2016/1-3). After informed about the study, informed consent was taken from all participants.

The study group consisted of 81 patients diagnosed with COME. The control group consisted of 81 healthy children. Two groups were formed by layering-stratification in such a way that the average age, gender, and adenoid tissue size were equal. Children with hearing loss lasting at least three months were assessed by otoscopic examination and tympanogram. Patients with tympanic nodularity, retraction, air fluid level, hypervascularization were confirmed by tympanogram. Those with type B tympanogram were included in the study.

Adenoid sizes of patients were scored between 1-4 according to adenoid tissue/nasopharyngeal ratio using flexible fiberoptic nasopharyngoscopy; 1 . $0-25 \%, 2.25-50 \%$, 3. $50-75 \%$, and $4.75-$ $100 \%{ }^{7}$ Blood samples were taken from the patients for Hgb, MCV, serum iron, and ferritin, which are the most important parameters in the diagnosis of iron deficiency anemia. C-reactive protein (CRP) was also routinely measured for infection. Because iron is an acute phase reactant, patients with active infection were removed from the study. Clinic, hemogram, and CRP values were taken into account when infection was detected. Any individuals with anatomic variation, such as cleft palate, or any other disease, were removed from the study. $\mathrm{Hgb}, \mathrm{MCV}$, serum iron, and ferritin values were compared between the study group and the control group.

\section{Statistical analysis}

The data were analyzed using SPSS (Chicago, Illinois, USA). Data are presented as numbers, percentages, and mean \pm standard deviation ( $95 \%$ confidence intervals). The Kolmogorov-Smirnov test was used to determine the normality of the data distributions. The paired t-test was used to compare the groups. A P value $<.05$ was considered significant.

\section{Results}

Of the 81 patients, 48 were males and 33 were females; 17 had unilateral serous otitis and the mean age was $8.1 \pm 0.3$ (from 2-15). The mean adenoid tissue size was $1.9 \pm 0.1$. The gender distribution and average age and adenoid tissue size were statistically identical between the control and study groups (Table 1). 
Table I Patient Demographics

\begin{tabular}{llllll}
\hline Group & Gender & No. & Percentage & Age(Mean) & $\begin{array}{l}\text { Adenoid } \\
\text { vegetation }\end{array}$ \\
\hline COME & Male & 48 & 59 & & \\
Group & Female & 33 & 41 & & \\
& Total & 81 & 100 & 8.1 & 1.9 \\
Control & Male & 48 & 59 & & \\
Group & Female & 33 & 41 & & \\
& Total & 81 & 100 & 8.1 & 1.9 \\
P value & & & $>.05$ & $>.05$ & $>.05$ \\
\hline
\end{tabular}

COME, chronic otitis media with effusion.

In the COME group, the mean Hgb was $13.4 \pm 0.9 \mathrm{~g} / \mathrm{dl}$ and in the control group it was $14.1 \pm 1.1 \mathrm{~g} / \mathrm{dl}$. There was no statistically significant difference ( $\mathrm{p}=0.178)$, although $\mathrm{Hgb}$ was low in the COME group. Similarly, there was no statistically significant difference in $\mathrm{MCV}$, serum iron, and ferritin values, although the three results were low in the COME group (Table 2).

Table 2 Comparison of $\mathrm{Hgb}, \mathrm{MCV}$, serum iron and ferritin values between groups

\begin{tabular}{lllll}
\hline Group & Hgb & MCV & Serum iron & Ferritin \\
\hline COME Group & $13.4 \pm 0.9$ & $76.5 \pm 2.2$ & $74 \pm 3.5$ & $49.9 \pm 5.1$ \\
Control Group & $\mid 4.1 \pm 1.1$ & $79.2 \pm 1.7$ & $78.9 \pm 3.3$ & $53.4 \pm 6.7$ \\
$P$ value & $=0.178$ & $=0.323$ & $=0.217$ & $=0.082$ \\
\hline
\end{tabular}

COME, chronic otitis media with effusion.

\section{Discussion}

Otitis media is the most common childhood disease after viral upper respiratory tract infection. ${ }^{8} \mathrm{OME}$ is an inflammatory response of the middle ear characterized by tympanic cavity effusion and no symptoms of acute infection. OME is generally seen after acute otitis media (AOM) and a three-month-long course is defined as COME. ${ }^{3,8}$

Age is reported to be the most important risk factor in the formation of COME. The incidence of the disease decreases with age, because over time the eustachian tube changes from a horizontal position to a vertical position. ${ }^{9}$ Sanli et al., ${ }^{8}$ found the highest incidence of COME among children aged 5-7 years. Adenoid vegetation is also important in the etiology of COME. Although the research findings are not entirely consistent, the general consensus is that adenoid vegetation increases the risk of COME. ${ }^{9,10}$ Risk factors include living in crowded conditions, premature birth, use of tobacco (active, passive), bottle feeding, young age at first incidence, poor socioeconomic status, history of OME in siblings or parents, poor overall health, history of AOM, season (winter, autumn), gastroesophageal reflux, and some genetic diseases (immune deficiency, cleft palate, silier dyskinesia, Down syndrome, cystic fibrosis). ${ }^{10,12}$ Frequency is not affected by gender. ${ }^{8}$ We found no differences between the study and control groups in terms of adenoid size, age, or gender.

Previous studies have explored the relationship between iron deficiency and infection resistance. The general view among pediatricians is that children with iron deficiency are more susceptible to infection. This situation is explained by two mechanisms: disruption of the inflammatory response of T-lymphocytes and reduction of the bactericidal effect of neutrophils.13-15 Rinaldo et al., ${ }^{16}$ described OME as a catarrhal effusion, and stated that neutrophils, macrophages, and lymphocytes (B- and T-lymphocytes) are the dominant cells in this infection. Therefore, it could be expected that the iron deficiency that disrupts the functions of these cells facilitates the formation of OME. Golz et al., ${ }^{17}$ found that anemia from iron deficiency increased the frequency of infection in children who had recurrent AOM. No other studies have investigated iron deficiency and middle ear infections in the literature. One study reported that $45 \%$ of children with AOM have effusion in the middle ear after 1 month of infection, and $10 \%$ after 3 months, ${ }^{18}$ so an increase in the frequency of AOM may indirectly increase the risk of developing COME.

In this study, patients with iron deficiency were consulted to pediatrician. Iron deficiency treatment was administered by pediatrician. But otitis media with effusion did not follow up after treatment. This was a shortcoming of the study. Also to reduce error, we excluded any individuals with any additional disease. However, one another limitation of the study was its lack of evaluation of other risk factors.

\section{Conclusion}

Overall, this study revealed that COME patients were not significantly more likely to have iron deficiency than healthy individuals. Therefore, we cannot conclude that iron deficiency is a risk factor for this disease. COME is not an active infection like $\mathrm{AOM}$, but iron deficiency may increase the frequency of AOM and indirectly increase the frequency of COME.

\section{Acknowledgments}

None.

\section{Conflict of interest}

The author declares that there is no conflict of interest.

\section{References}

1. Elbistanli MS, Kocak HE, Acipayam H, et al. The Predictive Value of Neutrophil-Lymphocyte and Platelet-Lymphocyte Ratio for the Effusion Viscosity in Otitis Media With Chronic Effusion. J Craniofac Surg. 2017;28(3):244-247.

2. Walker RE, Bartley J, Flint D, et al. Determination of chronic otitis media with effusion in preschool children: a case-control study. BMC Pediatrics. 2017; 17:4-9.

3. Gates GA, Klein JO, Lim DJ, et al. Recent advances in otitis media, 1: definitions, terminology, and classification of otitis media. Ann Otol Rhinol Laryngol Suppl. 2002;111:8-18.

4. Bennett KE, Haggard MP, Silva PA, et al. Behaviour and developmental effects of otitis media with effusion into the teens. Arch Dis Child. 2001;85(2):91-95.

5. World Health Organization. Iron deficiency anaemia assessment, prevention, and control. A guide for programme managers. Geneva: Switzerland: World Health Organization; 2001. p. 4-5.

6. Özdemir N. Iron deficiency anemia from diagnosis to treatment in children. Türk Ped Arș. 2015;50:11-19.

7. Li AM, Wong E, Kew J, et al. Use of tonsil size in the evaluation of obstructive sleep apnea. Arch Dis Child. 2002;87(2):156-159. 
8. Sanli A, Tasdemir O, Eken M, et al. Prevalence of Otitis Media with Effusion Among Primary School Age-Children and Etiopathogenic Examination. Indian J Otolaryngol Head Neck Surg. 2014;66(Suppl 1):95-98

9. Hidayeti A, İnci E, Korkut $\mathrm{N}$, et al. Okul öncesi kreş çocuklarında efüzyonlu otitis media. Türk Otolarengoloji Arş. 2002;40(1):53-57.

10. Hergils L, Magnuson B. Morning pressure in the middle ear. Arch Otolaryngol. 198;111(2):86-89.

11. Sezgin Z. Otitis Media with Effusion: Overview of Diagnosis and Treatment Approaches. Pediatric Practice and Research. 2016;4(1):1-11.

12. Yüksel F, Doğan M, Karataş D, et al. Gastroesophageal reflux disease in children with chronic otitis media with effusion. J Craniofac Surg. $2013 ; 24(2): 380-383$.

13. Kulapongs P, Vithayasai V, Suskind R, et al. Cell mediated immunity and phagocytosis and killing function in children with severe iron deficiency anemia. Lancet. 1974;2(7882):689-691.
14. Walter T, Olivares M, Pizarro F,et al. Iron, anemia and infection. Nutr Rev. 1997;55(4):111-124.

15. Buckley RH. Iron deficiency anemia: Its relationship to infection susceptibility and host defense. J Pediatr. 1975;86:993-995.

16. Rinaldo A, Ferlito A. The pathology and clinical features of "glue ear": a review. Eur Arch Otorhinolaryngol. 2000;257:300-303.

17. Golz A, Netzer A, Goldenberg D, et al. The association between 1rondeficiency anemia and recurrant acute otitis media. Am J Otolaryngol. 2001;22(6):391-394.

18. Teele DW, Klein JO, Rosner B. Epidemiology of otitis media during the first seven years of life in children in greater Boston: a prospective, cohort study. J Infect Dis. 1989;160:83-94. 